\title{
Results of surgery for bronchial carcinoma in patients aged 70 and over
}

\author{
MICHAEL BATES \\ Department of Thoracic Surgery, North Middlesex Hospital, London, N.18
}

\begin{abstract}
The number of elderly patients who are developing carcinoma of the bronchus and who are also fit for surgical treatment is increasing. One hundred patients are reviewed who had operations for this condition. The histological distribution of growths in this age group is the same as in younger patients, and the rate of growth can be just as rapid. The importance of a high resectability rate and a low mortality rate in this age group is stressed. Pneumonectomy should be performed only for the strictest of reasons, as the mortality rate is too high, but the mortality rate for lobectomy is acceptable, and this is the operation of choice.
\end{abstract}

In an ageing population in which there is also an increasing incidence of bronchial carcinoma, one must expect to see more elderly patients who are suffering from this disease and whose good general condition justifies the consideration of surgical treatment. Most men or women who have reached the age of 70 can expect to live for a further 10 years. The fact that they have reached this age generally means that their condition is good, particularly their cardiovascular condition, and in many instances they are well able to stand, and benefit from, lung resection. Preferably this should be by lobectomy, a policy confirmed by Sensenig, Rossi, and Ehrenhaft (1966) when reviewing 59 patients of this age group subjected to thoracotomy at the University Hospital, Iowa City, between 1950 and 1960 .

The 100 patients who are reviewed in this paper were subjected to thoracotomy between August 1950 and February 1968, and their operations were performed at the North Middlesex Hospital, and Broomfield Hospital, Chelmsford. Of these patients, 88 had 89 resections, one patient having bilateral lower lobectomies.

\section{AGE AND SEX GROUPS}

Eighty-seven of these patients were in the 70-75 age group, but 13 of them were over the age of 75 and also very fit.

The sex distribution of 93 men to seven women is much the same as in the younger age groups.

\section{HISTOLOGY}

The histological distribution of the resected growths in this series is similar to that in the younger age groups (Table I).
T A B L E I

\begin{tabular}{|c|c|c|c|}
\hline \multicolumn{2}{|c|}{ Type of Growth } & \multirow{2}{*}{$\begin{array}{c}\text { No. Resected } \\
61 \\
16 \\
5 \\
6\end{array}$} & \multirow{2}{*}{$\begin{array}{c}\text { No. Inoperable } \\
4 \\
6 \\
2 \\
0\end{array}$} \\
\hline $\begin{array}{l}\text { Squamous-cell } \ldots \\
\text { Undifferentiated } \\
\text { Oat-cell } \cdots \\
\text { Adenocarcinoma }\end{array}$ & $\begin{array}{l}\cdots \\
\cdots \\
\cdots\end{array}$ & & \\
\hline & & 88 & 12 \\
\hline
\end{tabular}

Elderly patients may develop squamous-cell carcinomas which grow slowly, and this must be taken into consideration when advising thoracotomy. If there is evidence of a squamous origin to the growth, and also radiological evidence to show little enlargement over several months or even years, then the patient may live for at least five years and die from some other condition. Nevertheless bronchial carcinomas can grow just as rapidly in the elderly as in the younger patient.

This point was emphasized by Belcher and Anderson (1965), who devoted a section in their paper to patients in this age group when reviewing the results of surgery in a much larger series of 1,134 patients treated for bronchial carcinoma at the London Chest, the Middlesex, and Pinewood Hospitals between 1949 and 1963. There were 12 patients in whom the growth could not be removed at thoracotomy, and in six of them the growth was undifferentiated. The average duration of symptoms in these 12 inoperable cases from date of onset to thoracotomy was only 10 weeks, which confirms a rapid rate of growth.

It is essential to aim at a high resectability rate in this age group, and where a positive biopsy of undifferentiated or oat-cell growth is obtained from a main bronchus, then thoracotomy is probably not justified, as a thoracotomy alone carries 
a high morbidity rate for these particular patients. As a result of experience gained with the earlier patients in this group, there has been only one inoperable case in the last 35 thoracotomies, and this patient had an undifferentiated growth.

\section{OPERATION}

Of the 89 resections performed, 58 have been lobectomies for peripheral growths which presented either with haemoptysis, as malignant abscesses, as cases of hypertrophic pulmonary osteoarthropathy, or as symptom-free shadows on mass radiography.

Five patients had segmental resections for small growths without lymph node involvement, and in them it was important to preserve as much lung tissue as possible.

Twenty-six pneumonectomies were performed, most of these being in the earlier part of the series. It soon became evident that the hospital mortality for pneumonectomy was too high, consequently only three pneumonectomies have been performed in the last 36 resections.

\section{HOSPITAL DEATHS}

The highest mortality rate followed pneumonectomy, three patients out of nine dying after intrapericardial resections, and three out of 17 dying after extrapericardial resections. Elective tracheostomy is now performed after nearly every pneumonectomy in this age group, and this has been of benefit to the patient in the first postoperative week, after which the tube has been removed.

The eight post-lobectomy deaths were due to eight different reasons, ranging from pulmonary embolus to perforated gastric ulcer, paralytic ileus, and persistent low blood pressure from suprarena $\stackrel{\overrightarrow{\bar{\rho}}}{\frac{\rho^{\circ}}{6}}$ metastases.

There were no deaths in the five patients who $\frac{\overline{\frac{}{n}}}{\bar{n}}$ had segmental resections.

To justify surgery in this age group, a low mortality rate is essential, and pneumonectomyen should be performed for only the strictest of reasons. There have been no hospital deaths in thelast 36 operations, only three of which werew pneumonectomies.

A disappointingly large number of the resected $\overrightarrow{\vec{x}}$ patients die within one year of operation, eitherif from a recurrence of their carcinoma or fromcoronary artery disease. However, of those patients $y$ who survive the first year, a high proportion liveo for a worth-while length of time, and the quality? of survival is satisfactory. There are three patientsc who are alive and well 10 years after their operations, and two of them are aged 85 (Table II).

T A B L E I I

LATE DEATHS AND SURVIVORS

\begin{tabular}{l|r|r|r|r|r|r|r|}
\hline & \multicolumn{9}{|c}{ Survival (years) } \\
\cline { 2 - 7 } & $<1$ & $1-2$ & $2-3$ & $3-4$ & $4-5$ & $5+$ & $10+$ \\
\hline No. of deaths .. & 40 & 13 & 1 & 3 & 2 & 4 & 0 \\
No. of survivors & 0 & 7 & 4 & 4 & 2 & 5 & 3 \\
\hline
\end{tabular}

It is reasonable to suppose that an increasing number of patients in this older age group will be diagnosed as suffering from bronchial carcinoma, and there seems no reason why they should not undergo lung resection, preferably byo lobectomy.

\section{REFERENCES}

Belcher, J. R. and Anderson, R. (1965). Surgical treatment of car cinoma of the bronchus. Brit. med. J., 1, 948 .

Sensenig, D. M., Rossi, N. P., and Ehrenhaft, J. L. (1966). Pulmonary resection for bronchogenic carcinoma in geriatric patients. Ann.? thorac. Surg., 2, 508. 